\title{
Matrine reduces the proliferation of A549 cells via the p53/p21/PCNA/eIF4E signaling pathway
}

\author{
ZHIYAN LU ${ }^{1}$, YOUZHANG XIAO ${ }^{2}$, XING LIU $^{2,3}$, ZAIPENG ZHANG $^{1}$, FENG XIAO $^{2}$ and YONGYI BI ${ }^{3}$ \\ ${ }^{1}$ Department of Radiology, Zhongnan Hospital of Wuhan University, Wuhan, Hubei 430071; \\ ${ }^{2}$ Key Laboratory of Pharmaceutical Biotechnology, School of Medicine, Jinggangshan University, Ji'an, Jiangxi 343000; \\ ${ }^{3}$ Hubei Biomass-resource Chemistry and Environmental Biotechnology Key Laboratory, \\ School of Public Health, Wuhan University, Wuhan, Hubei 430071, P.R. China
}

Received June 19, 2015; Accepted April 19, 2016

DOI: $10.3892 / \mathrm{mmr} .2017 .6331$

\begin{abstract}
The aim of the present study was to investigate how matrine affects the proliferation of A549 human lung adenocarcinoma cells via the p53/p21/proliferating cell nuclear antigen (PCNA)/eukaryotic translation initiation factor 4E (eIF4E) signaling pathway. The effect of different concentrations of matrine on the proliferation of A549 cells was investigated using a 3-(4,5-dimethylthiazol-2-yl)-2,5-diphenyltetrazolium bromide (MTT) assay. The migration of A549 cells following exposure to varied concentrations of matrine was detected using a Transwell cell migration assay. The effect of $240 \mathrm{mg} / \mathrm{l}$ matrine on the apoptotic rate of A549 cells was determined using flow cytometry. The change in the mRNA and protein expression levels of p53, p21, PCNA and eIF4E following exposure to matrine were detected using reverse transcription-quantitative polymerase chain reaction and western blotting, respectively. The increase of matrine from $60-240 \mathrm{mg} / \mathrm{l}$ led to reduced cell migration and inhibition of A549 cell proliferation. The apoptotic rate of A549 cells when treated with $240 \mathrm{mg} / \mathrm{l}$ matrine was significantly different when compared with the untreated control. The mRNA expression levels of p53 and p21 in the group treated with $240 \mathrm{mg} / \mathrm{l}$ matrine were significantly higher compared with the control group. The mRNA expression levels of PCNA and eIF4E were significantly lower in
\end{abstract}

Correspondence to: Dr Feng Xiao, Key Laboratory of Pharmaceutical Biotechnology, School of Medicine, Jinggangshan University, 28 Xueyuan Road, Ji'an, Jiangxi 343000, P.R. China

E-mail: xiaofeng1008@126.com

Dr Yongyi Bi, Hubei Biomass-resource Chemistry and Environmental Biotechnology Key Laboratory, School of Public Health, Wuhan University, 115 Donghu Road, Wuhan, Hubei 430071, P.R. China

E-mail: yongyib@yahoo.com.cn

Key words: matrine, cells proliferation, p53, p21, proliferating cell nuclear antigen, eukaryotic translation initiation factor 4E, A549 cells the $240 \mathrm{mg} / \mathrm{l}$ matrine-treated group compared with the control. The protein expression levels of p53 and p 21 were significantly higher in the $240 \mathrm{mg} / \mathrm{l}$ matrine group compared with the control group. Treatment with $240 \mathrm{mg} / \mathrm{l}$ matrine reduced the protein expression levels of PCNA and eIF4E. Matrine also reduced the migration ability of A549 cells and inhibited their proliferation, which may be associated with the overexpression of p53 and p21, and the reduction of PCNA and eIF4E expression levels.

\section{Introduction}

Lung cancer is one of the frequent clinical malignancies (1). Chemotherapy has been adopted as the primary treatment method. However, the majority of lung cancer patients have not been sufficiently sensitive to traditional chemotherapy treatment (2). Matrine $\left(\mathrm{C}_{15} \mathrm{H}_{24} \mathrm{~N}_{2} \mathrm{O}\right)$ is analkaloid (3), which may inhibit the proliferation of A549 human lung adenocarcinoma cells (4) and non-small-cell lung cancer cells (5).

p53 is a well-known tumor suppressor gene (6), and in numerous types of cancer patients often have a dysfunctional p53 (7). p21 is an important member of the Cip family (8) and the cyclin-dependent kinase inhibitor family (9). A mutation in the p21 gene is associated with pancreatic cancer (10) and the differentiation of other malignant tumor types, including to the depth of invasion, proliferation and metastasis. Additionally, p21 has prognostic value; p21 expression has been documented as a poor prognostic marker in human lung cancer (11). Proliferating cell nuclear antigen (PCNA) is a protein expressed in proliferative stage cells or tumor cells (12). PCNA expression levels have been observed to change periodically throughout the cell cycle (13). The detection of PCNA expression in cells may be used as an indicator of the proliferation status of pancreatic cancer cells (14). Eukaryotic initiation factor 4E (eIF4E) is a cytokine associated with pancreatic cancer (15) and other malignant tumor types, which is important in the initiation of protein synthesis (16) and is closely associated with tumorigenesis, invasion and metastasis.

Therefore, the present study investigated if matrine is capable of reducing the proliferation of A549 lung cancer cells via the $\mathrm{p} 53 / \mathrm{p} 21 / \mathrm{PCNA} / \mathrm{eIF} 4 \mathrm{E}$ signaling pathway. 


\section{Materials and methods}

Cell culture. Human lung adenocarcinoma A549 cells, were obtained from the Chinese Academy of Medical Sciences Tumor Cell Bank (Beijing, China). These cells were maintained in RPMI-1640 medium (Gibco; Thermo Fisher Scientific, Inc., Waltham, MA, USA), supplemented with $10 \%$ fetal bovine serum (Gibco; Thermo Fisher Scientific, Inc.) and incubated at $37^{\circ} \mathrm{C}$ in a $5 \% \mathrm{CO}_{2}$ atmosphere.

Cell toxicity and proliferation assays. Adherent A549 cells were cultured by digestion. The cells were seeded at a density of $1.0 \times 10^{5}$ cells/well into 96-well plates. A control group and four groups of cells treated with different concentrations (60, 120, 180 and $240 \mathrm{mg} / \mathrm{l}$ ) of matrine (National Institute for the Control of Pharmaceutical and Biological Products, Beijing, China) were used. The control group was exposed to identical quantities of medium. The drug was diluted with distilled water and served as a vehicle control. Every $48 \mathrm{~h}$, the medium was replaced with fresh medium containing the specified concentration of the drug. The cell groups were cultured for 6 days. A total of $20 \mu \mathrm{l}(5 \mathrm{mg} / \mathrm{ml}) 3$-(4,5-dimethylthiazol-2-yl)-2,5-diphenyltetrazolium bromide (MTT; Hangzhou Sijiqing Biological Engineering Materials Co., Ltd., Hangzhou, China) were added to each well, and the samples were incubated for $4 \mathrm{~h}$ at $37^{\circ} \mathrm{C}$. Following incubation, the absorbance (A) values of the microplate wells were determined at $570 \mathrm{~nm}$. Cell proliferation inhibition rate $=\left(1-\mathrm{A}_{\text {treatment group }} / \mathrm{A}_{\text {control group }}\right) \times 100$.

Transwell assay. Cells were seeded at $4 \times 10^{5} / \mathrm{ml}$ in two 6-well plates and treated with $1 \mathrm{ml} 10 \% \mathrm{FBS}, 1 \%$ penicillin/streptomycin and RPMI-1640. After $24 \mathrm{~h}$, varying concentrations (60, 120,180 and $240 \mathrm{mg} / \mathrm{l}$ ) of matrine were administered to the different groups and the cells were maintained at $37^{\circ} \mathrm{C}$ for $48 \mathrm{~h}$. The top of the transwell chamber contained $150 \mu \mathrm{l}$ suspension $\left(1 \times 10^{6} \mathrm{cell} / \mathrm{ml}\right)$, and the bottom contained $600 \mu 110 \%$ FBS. The cells were gently removed from the top chamber with a cotton swab prior to staining with crystal violet. A total of three visual fields were randomly selected and images were captured using a fluorescence microscope (BX53; Olympus Corporation, Tokyo, Japan). Migrating cells were counted and statistical analysis was performed on the data obtained. The inhibition of cell migration inhibition $=(1-$ number of migrated cells in the intervention group / number of migrating cells in the control group) x 100 .

Flow cytometry. The A549 cell suspension $\left(3 \times 10^{4} / \mathrm{ml}\right)$ was placed at $2 \mathrm{ml}$ per well into a 6 -well plate and incubated for $12 \mathrm{~h}$ at $37^{\circ} \mathrm{C}$ in a an atmosphere of $5 \% \mathrm{CO}_{2}$. After $12 \mathrm{~h}$, the media was aspirated and the matrine was added at the aforementioned concentrations. Media with no cell suspension served as a blank control. Each treatment was performed in triplicate. The cells were trypsinized and collected, washed with cold phosphate-buffered saline (PBS) twice and $100 \mu \mathrm{l} 1 \mathrm{X}$ annexinbinding buffer (Nanjing KeyGen Biotech Co., Ltd., Nanjing, China) was added. Annexin V (5 $\mu \mathrm{l})$ was added, followed by $100 \mu \mathrm{g} / \mathrm{ml}$ propidium iodide $(1 \mu \mathrm{l})$. Following a 15 -min incubation in the dark at room temperature, $400 \mu \mathrm{l} 1 \mathrm{X}$ annexin-binding buffer was added. Flow cytometry was performed using a BD FACSVerse $^{\mathrm{TM}}$, BD Biosciences, Franklin Lakes, NJ, USA).

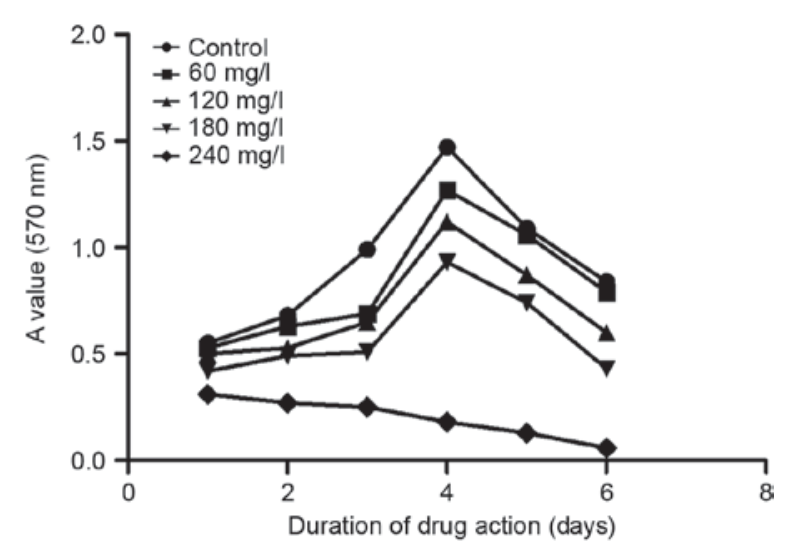

Figure 1. Growth curve of human lung adenocarcinoma A549 cells following treatment with various concentrations of matrine. A, absorbance.

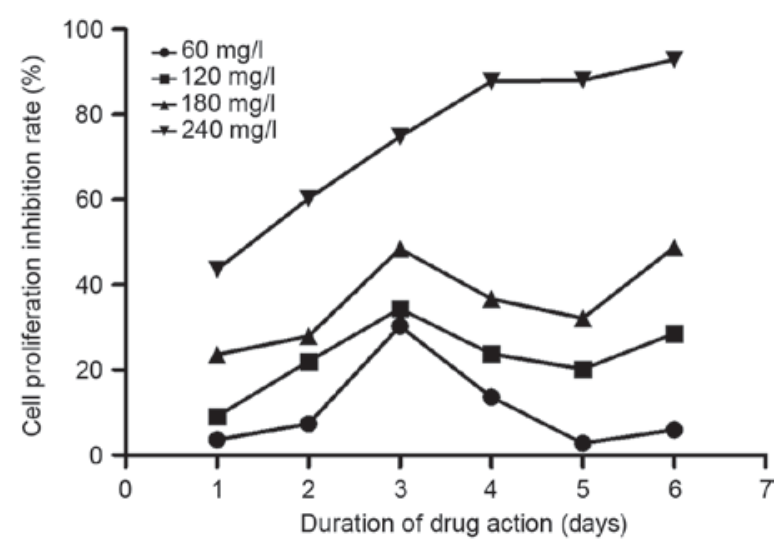

Figure 2. Inhibitory rate, relative to the control, of the proliferation of human lung adenocarcinoma A549 cells treated with matrine at different time points.

Reverse transcription-quantitative polymerase chain reaction (RT-qPCR). Following treatment, the A549 cells were collected from the control group and the group treated with $240 \mathrm{mg} / \mathrm{l}$ matrine. The total RNA was extracted using TRIzol reagent (Thermo Fisher Scientific, Inc.) and was reverse transcribed to obtain cDNA. $\beta$-actin was used as an internal reference. The qPCR primers ( $\beta$-actin, p53, p21, PCNA and eIF4E) were synthesized by the Shanghai Biological Engineering Technology Services Limited (Table I). The CFX Connect Real-Time PCR system (Bio-Rad Laboratories, Inc., Hercules, CA, USA) and the CFX Manager (Bio-Rad Laboratories, Inc.) were used for analysis according to the manufacturer's instructions. Each reaction contained $500 \mathrm{ng} \mathrm{cDNA}, 10 \mu \mathrm{l}$ of $2 \mathrm{X}$ master mix, $0.5 \mu \mathrm{l}$ primers and water for a final volume of $30 \mu \mathrm{l}$. A SuperReal Premix Plus (SYBR Green) from Tiangen Biotech Co., Ltd. (Beijing, China) was used. The threshold cycle value, that represents the cycle number at which sample fluorescence rises to a statistically significant level above the background, was calculated. CFX Manager uses the comparative Cq method for relative quantitative analysis, and the gene expression levels are presented as a fold change (17). All amplifications were run in triplicate and the mean value was applied for all calculations.

Western blotting. The cells were cultured for $24 \mathrm{~h}$ in 6-well plates at a density of $1.0 \times 10^{6} \mathrm{cells} / \mathrm{cm}^{2}$. Following incubation, the cells were collected and washed three times with ice-cold PBS. 
Table I. Primer sequences for polymerase chain reaction.

\begin{tabular}{llll}
\hline Gene & \multicolumn{1}{c}{ Forward (5'-3') } & Reverse (5'-3') & Length (bp) \\
\hline$\beta$-actin & CCCATCTATGAGGGTTACGC & TTTAATGTCACGCACGATTTC & 150 \\
p53 & ACCTATGGAAACTACTTCCTGAAA & CTGGCATTCTGGGAGCTTCA & 141 \\
p21 & AGTCAGTTCCTTGTGGAGCC & CATTAGCGCATCACAGTCGC & 184 \\
PCNA & CAGAGCTCTTCCCTTACGCA & GTCCTTGAGTGCCTCCAACA & 200 \\
eIF4E & TTCCTTCTGACTGGGGGACT & CCTCCTCTGTAGTCGGGGGA & 192 \\
\hline
\end{tabular}

PCNA, proliferating cell nuclear antigen; eIF4E, eukaryotic translation initiation factor 4E.

A

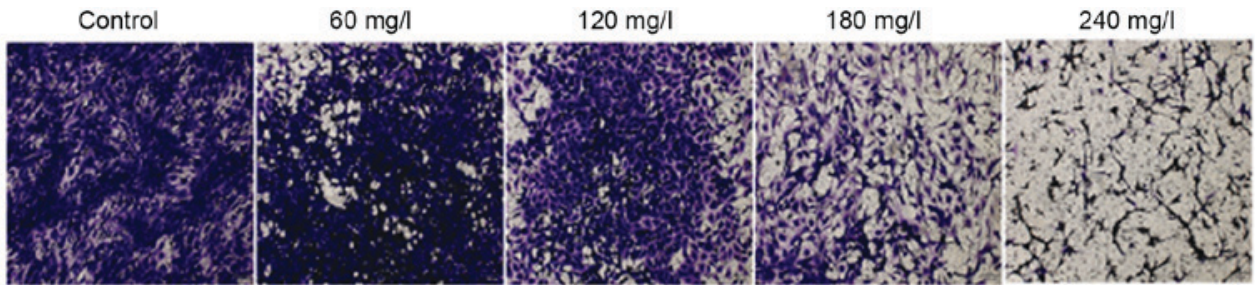

B

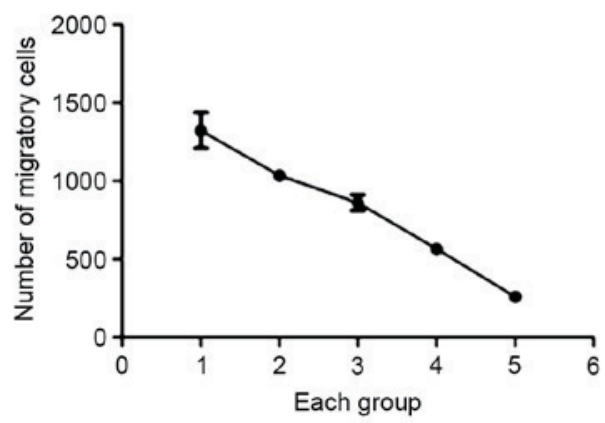

C

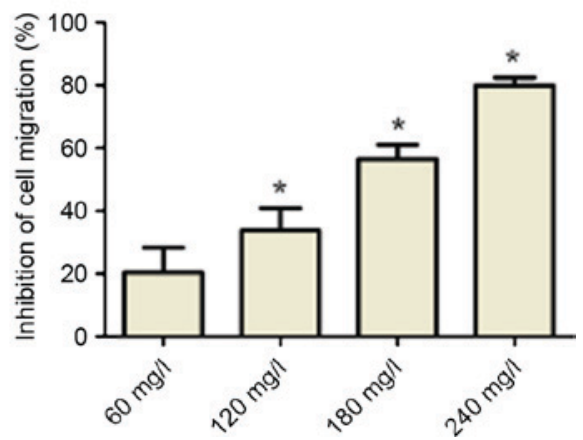

Figure 3. Inhibitory action of matrine on the migration of human lung adenocarcinoma A549 cells. (A) Representative images of cell migration following treatment with matrine (magnification, x200). (B) Cells were treated with an increasing concentration of matrine (group 1, control; group 2, 60 mg/l; group 3, $120 \mathrm{mg} / 1$; group 4, $180 \mathrm{mg} / 1$; group 5, $240 \mathrm{mg} / \mathrm{l})$. The number of cells migrating through were calculated and (C) the percentage of inhibition was determined relative to the control. The data are presented as the mean \pm standard deviation $\left({ }^{*} \mathrm{P}<0.05 \mathrm{vs} .60 \mathrm{mg} / \mathrm{l}\right)$.

A

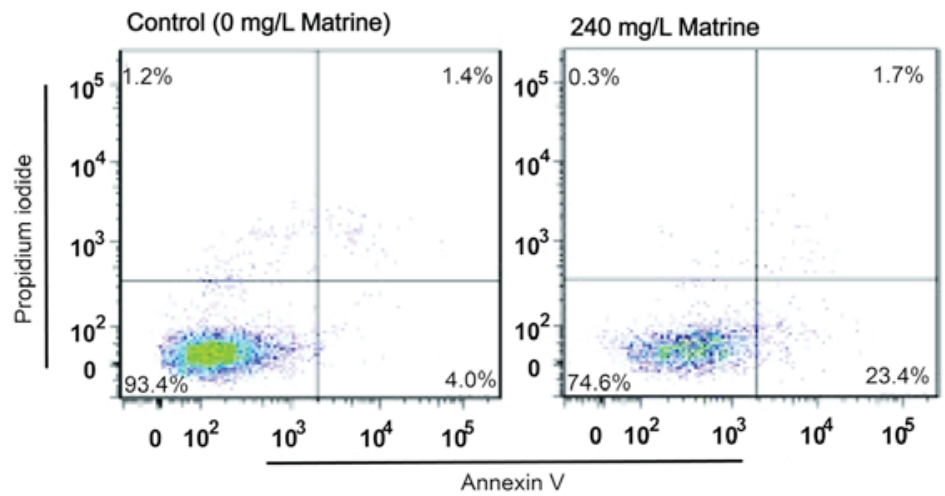

B

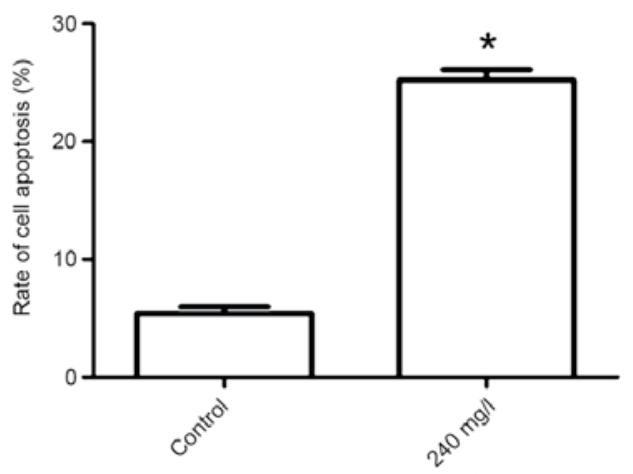

Figure 4. Matrine induces the apoptosis of A549 cells. (A) Flow cytometry revealed that apoptosis was induced following treatment with matrine. Percentage of live (lower left), early apoptotic (lower right) and late apoptotic (upper right) populations are indicated. (B) The rate of apoptosis was determined (* $\mathrm{P}<0.05 \mathrm{vs}$. control).

The cells were subsequently centrifuged for $5 \mathrm{~min}$ at $300 \mathrm{x} \mathrm{g}$, and the supernatant was discarded. The total protein was extracted using RIPA (Thermo Fisher Scientific, Inc.) according to the manufacturer's protocol. Protein concentration was determined using the bicinchoninic acid assay method (Enhanced BCA Protein assay kit; Beyotime Institute of Biotechnology, 
A

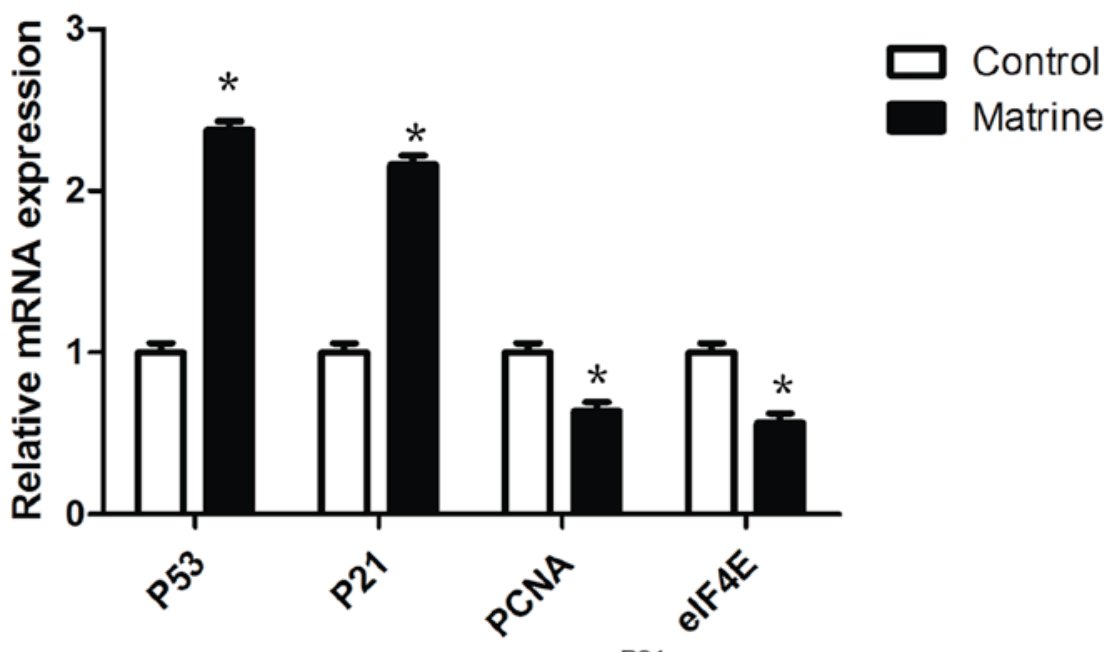

B
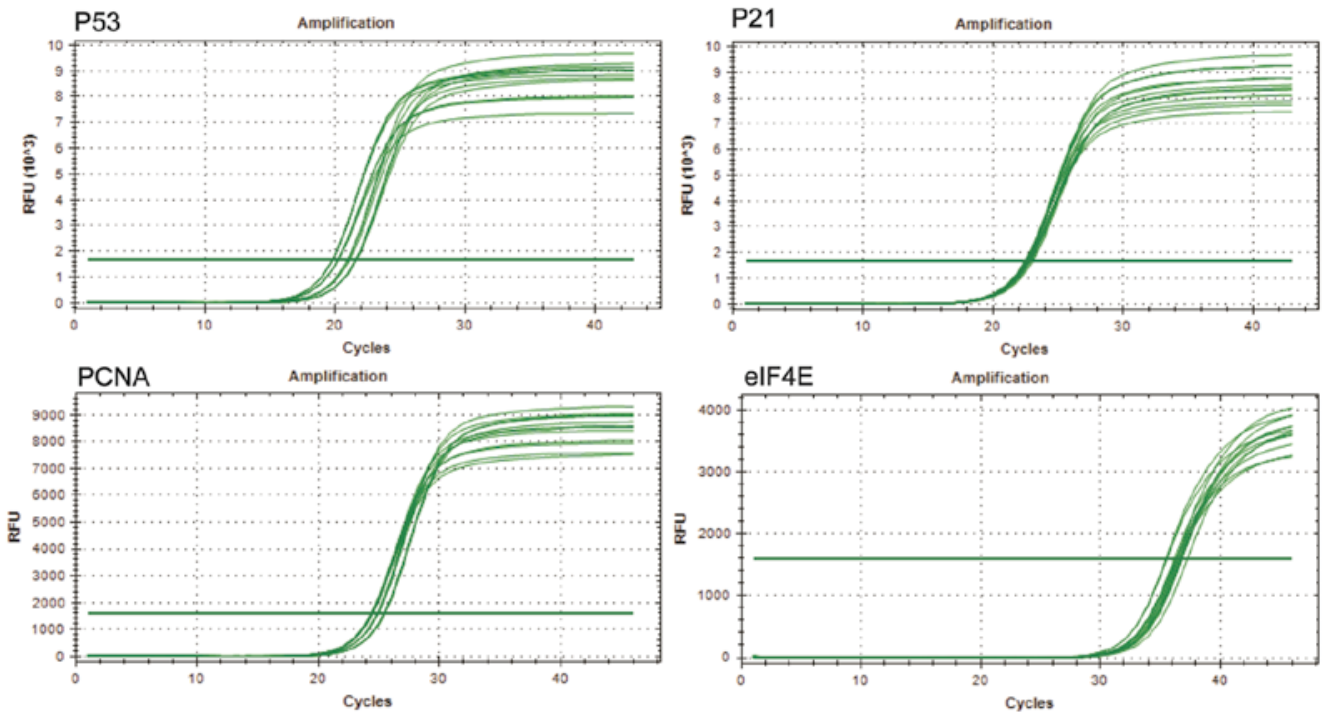

C
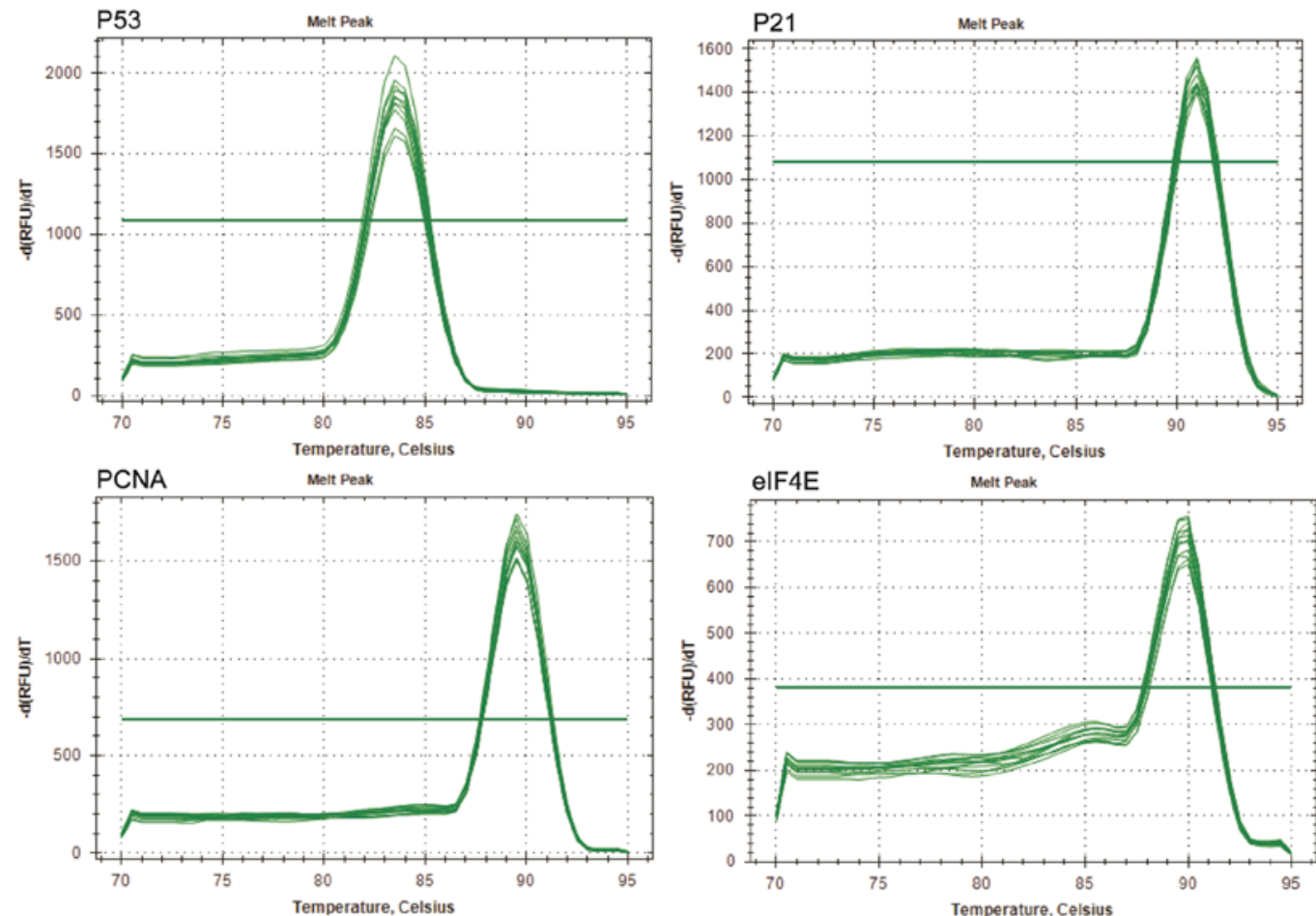

Figure 5. Reverse transcription-quantitative polymerase chain reaction. (A) Effect of matrine treatment on the mRNA expression levels of p53, p21, PCNA, and eIF4E ("P<0.05 vs. control). (B) Amplification and (C) melting curves. PCNA, proliferating cell nuclear antigen; eIF4E, eukaryotic translation initiation factor 4E; RFU, relative fluorescence unit. 
Shanghai, China). Aliquots of $150 \mu \mathrm{g}$ total protein were separated by $8 \%$ polyacrylamide gel electrophoresis. Tris-buffered saline/Tween-20 solution containing $1 \%$ bovine serum albumin (Sangon Biotech Co., Ltd., Shanghai, China) and non-fat milk was used to block the membranes overnight at $4^{\circ} \mathrm{C}$. Following blocking, the membranes were incubated with the following primary antibodies at a dilution of 1:1,000: Polyclonal rabbit anti-p53 (cat. no. sc-6243), polyclonal rabbit anti-PCNA (cat. no. sc-7907), monoclonal mouse anti-p21 (cat. no. sc-271532) and monoclonal mouse anti-eIF4E (cat. no. sc-271480; Santa Cruz Biotechnology, Inc. Santa Cruz, CA, USA). The $\beta$-actin antibody (cat. no. sc-47778; dilution, 1:2,000 from Santa Cruz Biotechnology, Inc.) served as the loading control. The proteins were visualized using the following secondary antibodies: Goat anti-rabbit (1:4,000; cat. no. bs-0295G) and goat anti-mouse (1:4,000; cat. no. bs-0368Gs) antibody, purchased from Beijing Biosynthesis Biotechnology Co., Ltd. (Beijing, China). The bands were developed using an ECL system according to the manufacturer's protocols. ImageJ 1.48 software (National Institutes of Health, Bethesda, MD, USA) was used to determine the density of the bands in all blots.

Statistical analysis. When comparing two groups of data a paired samples t-test was performed. When comparing multiple groups a one-way analysis of variance followed by a post-hoc Tukey's test was used. Statistical analyses were conducted using SPSS version 22.0 (IBM SPSS, Armonk, NY, USA) and data are presented as means \pm standard deviation. $\mathrm{P}<0.05$ was considered to indicate a statistically significant difference.

\section{Results}

Inhibitory action of matrine on A549 cell proliferation. A549 cells were treated with different concentrations of matrine $(0,60,120,180$ and $240 \mathrm{mg} / \mathrm{l})$ for 6 days. The A570 values in each group were measured using an MTT assay and the obtained data were utilized to produce a growth curve (Fig. 1).

As shown in Fig. 2, matrine could effectively inhibit A549 cell proliferation. At each time point, matrine exerted inhibitory effects in a dose-dependent manner, from $60-240 \mathrm{mg} / \mathrm{l}$. In addition, on day 3 following treatment, the inhibition reached its maximum at all concentrations except for $240 \mathrm{mg} / \mathrm{l}$. Based on this observation, one possible explanation is that between days 3 and 4, the cells had already occupied all the culturing space and could not proliferate any further; therefore, the inhibitory rate dropped on day 4 .

Matrine inhibits cell migration. As depicted in Fig. 3, A549 cell migration was reduced as the concentration of matrine was increased. Therefore, the inhibition rate of cell migration increased in a dose-dependent manner.

Apoptosis is increased in cells treated with a high concentration of matrine. Based on the growth curve of A549 cells (Fig. 1), matrine at $240 \mathrm{mg} / \mathrm{l}$ exhibited the strongest inhibitory effects $48 \mathrm{~h}$ after treatment; therefore, $240 \mathrm{mg} / \mathrm{l}$ of matrine was chosen as the treatment condition. Even higher concentrations of matrine may lead to early cell death, thus indicating that other types of cell death may have occurred. Therefore, only

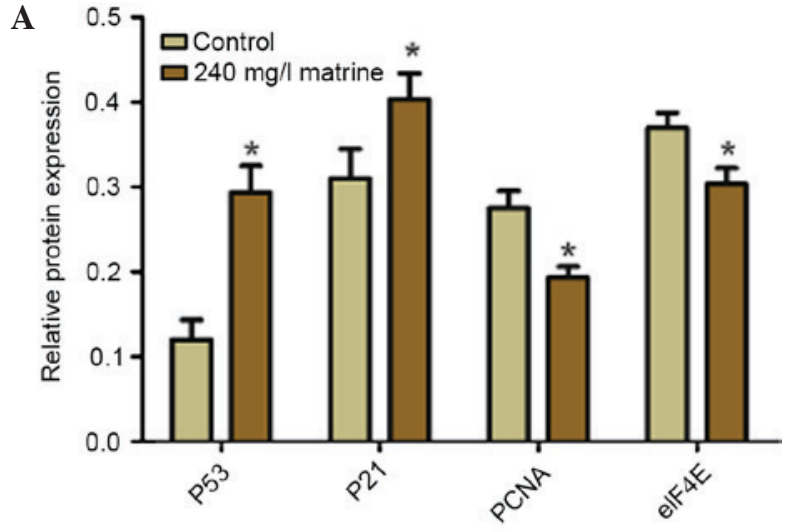

B

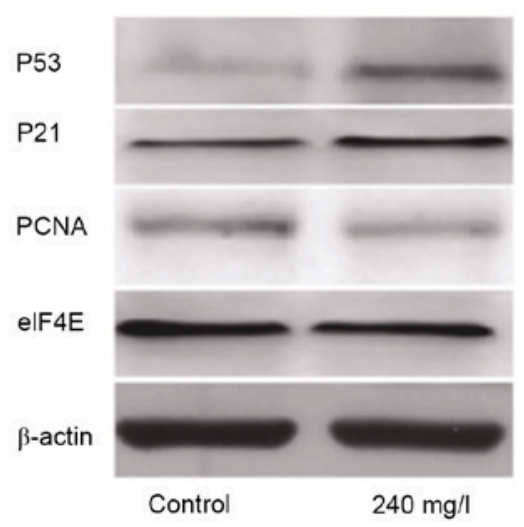

Figure 6. Effect of matrine on the protein expression levels of p53, p21, PCNA and eIF4E ( ${ }^{*} \mathrm{P}<0.05$ vs. control). Western blotting was performed to determine the protein expression levels of certain proteins following treatment with $240 \mathrm{mg} / 1$ matrine. (A) The relative protein expression levels were determined. $\beta$-actin was used as a loading control. (B) Representative western blot images. PCNA, proliferating cell nuclear antigen; eIF4E, eukaryotic translation initiation factor $4 \mathrm{E}$.

$240 \mathrm{mg} / \mathrm{l}$ matrine was used to treat cells in the apoptosis assay. A549 cells were treated with $240 \mathrm{mg} / \mathrm{l}$ matrine in order to investigate its effect on the apoptotic rate compared with that of the control group. Flow cytometry indicated (Fig. 4) that the apoptotic rate in the $240 \mathrm{mg} / \mathrm{l}$ matrine-treated group was significantly higher when compared with the control group $(\mathrm{P}<0.05)$.

Matrine treatment increases the mRNA expression levels of p53 and p21, whilst reducing that of PCNA and eIF4E. The RT-qPCR findings indicated that the mRNA expression levels of p53 and p21 were significantly higher in the $240 \mathrm{mg} / \mathrm{l}$ matrine group compared with the control group $(\mathrm{P}<0.05$; Fig. 5A). The mRNA expression levels of PCNA and eIF4E were significantly lower in the $240 \mathrm{mg} / \mathrm{l}$ matrine group compared with the control $(\mathrm{P}<0.05)$.

The Cq values of the RT-qPCR amplification curves of p53, p21, PCNA and eIF4E genes (Fig. 5B) were between 20 and 40 . The results indicated that the p53, p21, PCNA and eIF4E have been successfully amplified. There was a steep peak in all RT-qPCR amplification curves, indicating that only one DNA product was formed during the reaction.

Matrine treatment increases the protein expression levels of p53 and p21, whilst reducing that of PCNA and eIF4E. 
Western blot analysis (Fig. 6) revealed that the protein expression levels of p53 and p21 were significantly higher in the $240 \mathrm{mg} / \mathrm{l}$ matrine-treated group compared with the control group $(\mathrm{P}<0.05)$. The protein expression levels of PCNA and eIF4E were significantly lower in the $240 \mathrm{mg} / 1$ matrine-treated group compared with the control group $(\mathrm{P}<0.05)$.

\section{Discussion}

Matrine $\left(\mathrm{C}_{15} \mathrm{H}_{24} \mathrm{~N}_{2} \mathrm{O}\right)$ is usually derived from the legume, Sophora flavescens Ait (18), however the bioactive compound may also be extracted from other species belonging to the same genus, including Sophora subprostrata (19) and Sophora alopecuroides (20). Matrine exerts excellent pharmacological activity and is beneficial for lowering body temperature, promoting diuresis, detoxifying, treating jaundice and preventing liver fibrosis. Previous studies indicated that matrine may be used as an effective treatment for various types of cancer, including liver (21) and lung cancer (22), gastric (23) and colon cancer (24), cervical cancer (25), leukemia (26), osteosarcoma (27), glioma (28) and nasopharyngeal carcinoma (29), and exhibits potent activity against various other types of cancer. Lung cancer occurs in the bronchial epithelium (30) and is characterized by a high morbidity rate (31), a considerable degree of malignancy, a great metastatic propensity in the early stages and the tendency to recur following tumor excision (32). The present study aimed to investigate the effects of matrine on the proliferation of A549 human lung adenocarcinoma cells and on the mRNA and protein expression levels of p53, p21, PCNA and eIF4E. Additionally the current study aimed to determine the possible mechanisms by which matrine affects in order to inhibit A549 cell proliferation.

The main cell invasion and metastasis processes of A549 human lung adenocarcinoma cells and other tumor cells involves the adhesion of tumor cells to the basement membrane, which leads to the degradation of the extracellular matrix, promoting migration and invasion of cancerous cells, resulting in metastasis. Therefore, in the event that any of these stages are inhibited, the metastasis process would likely be inhibited, leading to of human lung adenocarcinoma A549 cells.

Initially, the present study used different concentrations $(60,120,180$ and $240 \mathrm{mg} / \mathrm{l})$ of matrine as a preliminary dosage. Via growth curves, it was established that all matrine concentrations used had a slight effect on the proliferation of A549 human lung adenocarcinoma cells. However, the most marked effect was in cells treated with $240 \mathrm{mg} / 1$ matrine

Migration of A549 cells and other tumor cells is an important stage between the invasion and metastasis progression. Therefore, Transwell cell migration experiments were used to determine the influence of 60, 120, 180 and $240 \mathrm{mg} / \mathrm{l}$ matrine on A549 lung cancer cell migration. As matrine concentration was increased, the rate of A549 cell migration was inhibited in a dose-dependent manner.

Apoptosis is a fundamental biological phenomenon in the cell life cycle, which has been important for the evolution of organisms as it allows for the removal of unhealthy or dysfunctional cells. The present study used flow cytometry to investigate the effect of $240 \mathrm{mg} / \mathrm{l}$ matrine on the apoptosis of A549 human lung adenocarcinoma cells. The results suggested that the apoptotic rate following the application of $240 \mathrm{mg} / \mathrm{l}$ matrine was significantly higher when compared with the control group. It was concluded that a concentration of $240 \mathrm{mg} / \mathrm{l}$ matrine induced considerable levels of apoptosis in A549 cells.

The p53 gene is a tumor suppressor gene (33), which is frequently termed a 'genetic guardian'. When DNA is damaged, the expression levels of p53 increase rapidly (34). If the p53 gene harbors a mutation, the activity of the p53 protein is reduced, leading to uncontrolled cell division and ultimately, the occurrence of cancer (35).

In recent years, p21 has been identified as an important member of the cyclin-dependent kinase inhibitor family (36), which is located downstream of the p53 gene (37). p21 and p53 contribute to the regulation of the G1 checkpoint of the cell cycle. As the damaged DNA cannot pass the G1 checkpoint without repair, the replication and the accumulation of damaged DNA can be reduced substantially. Therefore, the G1 checkpoint is important for tumor suppression (38). Previous studies $(11,22)$ have determined that the $\mathrm{p} 21$ gene is associated with tumor differentiation, depth of invasion, proliferation and metastasis of tumors, and is also valuable as a prognostic sign for tumor progression.

PCNA may be used as an indicator to evaluate the state of cell proliferation (39). A close association exists between PCNA and DNA synthesis (40). PCNA is also important for the initiation of cell proliferation. Previous experimental findings indicated that the expression of PCNA is associated with the stage of lung cancer, and in the later phases of lung cancer progression, the expression of PCNA is higher (41).

eIF4E is a cap-binding protein (42), which is important for the initial process of translation in eukaryotes. It is also closely associated with tumor occurrence, infiltration and metastasis; therefore, it is highly expressed in human lung cancer and various other malignancies (43).

In the present study, $\mathrm{RT}-\mathrm{qPCR}$ results indicated that the mRNA expression levels of p53 and p21 in the $240 \mathrm{mg} / \mathrm{l}$ matrine group were higher compared with the control group. Additionally, western blotting revealed that the protein expression levels of p53 and p21 in the $240 \mathrm{mg} / \mathrm{l}$ matrine group were also elevated compared with the control group. Therefore, matrine may promote the expression of p53 and p21 in A549 cells.

The RT-qPCR results also indicated that the mRNA expression levels of PCNA and eIF4E in the treatment group were lower compared with that in the control group. Furthermore, the reduction of PCNA and eIF4E expression levels following $240 \mathrm{mg} / 1$ matrine treatment, was less than that of the control group. Therefore, it is possible that matrine inhibits the gene expression of PCNA and eIF4E in A549 cells.

In conclusion, the findings of the present study indicated that matrine may inhibit the proliferation of A549 cells. The underlying mechanism may be associated with the induction of the expression levels of p53 and p21, and the inhibitory effect of matrine on the mRNA expression levels of PCNA and eIF4E. PCNA activity in DNA repair increases resistance to chemotherapy, and activation of p53 in response to DNA damage is correlated with a rapid increase in p53 expression level and enhanced p53 binding to DNA. This leads to the activation of 
various genes, including $\mathrm{p} 21$, and affects the phosphorylation of the eIF4E binding protein. The present study provides evidence that matrine-induced apoptosis and growth inhibition of lung cancer cells may be mediated by $\mathrm{p} 53$ activation, suggesting that matrine may serve as an adjuvant chemotherapeutic agent for lung cancer.

\section{Acknowledgements}

The present study was supported by the Science and Technology Department of Hubei Province (no. 20001P1804), the Natural Science Foundation of Jiangxi Province (no. 20122BAB205077) and the Natural Science Youth Foundation of Jiangxi Province (no. 20122BAB215042).

\section{References}

1. Amorin Kajatt E: Lung cancer: A review of current knowledge, diagnostic methods and therapeutic perspectives. Rev Peru Med Exp Salud Publica 30: 85-92, 2013 (In Spanish).

2. Spaans JN and Goss GD: Drug resistance to molecular targeted therapy and its consequences for treatment decisions in non-small-cell lung cancer. Front Oncol 4: 190, 2014.

3. Lu ZG, Li MH, Wang JS, Wei DD, Liu QW and Kong LY: Developmental toxicity and neurotoxicity of two matrine-type alkaloids, matrine and sophocarpine, in zebrafish (Danio rerio) embryos/larvae. Reprod Toxicol 47: 33-41, 2014.

4. Liu YQ, Li Y, Qin J, Wang Q, She YL, Luo YL, He JX, Li JY and Xie XD: Matrine reduces proliferation of human lung cancer cells by inducing apoptosis and changing miRNA expression profiles. Asian Pac J Cancer Prev 15: 2169-2177, 2014.

5. Yang CL, Liu SS, Ma YG, Liu YY, Xue YX and Huang B The influence of intraoperative pleural perfusion with matrine-cisplatin or cisplatin on stromal cell-derived factor-1 in non-small cell lung cancer patients with subclinical pleural metastasis. Med Oncol 29: 574-581, 2012.

6. Rogler CE and Chisari FV: Cellular and molecular mechanisms of hepatocarcinogenesis. Semin Liver Dis 12: 265-278, 1992.

7. Dong M, Nio Y, Yamasawa K, Toga T, Yue L and Harada T: p53 alteration is not an independent prognostic indicator, but affects the efficacy of adjuvant chemotherapy in human pancreatic cancer. J Surg Oncol 82: 111-120, 2003.

8. Matsui TA, Sowa Y, Murata H, Takagi K, Nakanishi R, Aoki S, Yoshikawa M, Kobayashi M, Sakabe T, Kubo T and Sakai T: The plant alkaloid cryptolepine induces p21WAF1/CIP1 and cell cycle arrest in a human osteosarcoma cell line. Int J Oncol 31: 915-922, 2007.

9. Fecteau JF, Corral LG, Ghia EM, Gaidarova S, Futalan D, Bharati IS, Cathers B, Schwaederlé M, Cui B, Lopez-Girona A, et al: Lenalidomide inhibits the proliferation of CLL cells via a cereblon/p21 (WAF1/Cip1)-dependent mechanism independent of functional p53. Blood 124: 1637-1644, 2014.

10. Yeo D, He H, Baldwin GS and Nikfarjam M: The role of p21-activated kinases in pancreatic cancer. Pancreas 44: 363-369, 2015

11. Xie D, Lan L, Huang K, Chen L, Xu C, Wang R, Shi Y, Wu X, Wang L, Liu Y and Lu B: Association of p53/p21 expression and cigarette smoking with tumor progression and poor prognosis in non-small cell lung cancer patients. Oncol Rep 32: 2517-2526, 2014.

12. Freund G, Desplancq D, Stoessel A, Weinsanto R, Sibler AP, Robin G, Martineau P, Didier P, Wagner J and Weiss E: Generation of an intrabody-based reagent suitable for imaging endogenous proliferating cell nuclear antigen in living cancer cells. J Mol Recognit 27: 549-558, 2014.

13. Halvorsen OJ: Molecular and prognostic markers in prostate cancer. A study of cell-cycle regulators, angiogenesis and candidate markers. APMIS Suppl: 5-62, 2008

14. Liu Y, Bi T, Wang G, Dai W, Wu G, Qian L, Gao Q and Shen G: Lupeol inhibits proliferation and induces apoptosis of human pancreatic cancer PCNA-1 cells through AKT/ERK pathways. Naunyn Schmiedebergs Arch Pharmacol 388: 295-304, 2015.
15. Chakravarthy R, Clemens MJ, Pirianov G, Perdios N, Mudan S, Cartwright JE and Elia A: Role of the eIF4E binding protein 4E-BP1 in regulation of the sensitivity of human pancreatic cancer cells to TRAIL and celastrol-induced apoptosis. Biol Cell 105: 414-429, 2013.

16. Martineau Y, Azar R, Müller D, Lasfargues C, El Khawand S, Anesia R, Pelletier J, Bousquet C and Pyronnet S: Pancreatic tumours escape from translational control through 4E-BP1 loss. Oncogene 33: 1367-1374, 2014.

17. Livak KJ and Schmittgen TD: Analysis of relative gene expression data using real-time quantitative PCR and the 2(-Delta Delta C(T)) Method. Methods 25: 402-408, 2001.

18. Bi W, Tian M and Row KH: Solid-phase extraction of matrine and oxymatrine from Sophora flavescens Ait using amino-imidazolium polymer. J Sep Sci 33: 1739-1745, 2010.

19. Cho CH, Chuang CY and Chen CF: Study of the antipyretic activity of matrine. A lupin alkaloid isolated from Sophora subprostrata. Planta Med: 343-345, 1986.

20. Wang H, Guo S, Qian D, Qian Y and Duan JA: Comparative analysis of quinolizidine alkaloids from different parts of Sophora alopecuroides seeds by UPLC-MS/MS. J Pharm Biomed Anal 67-68: 16-21, 2012.

21. Ou X, Chen Y, Cheng X, Zhang X and He Q: Potentiation of resveratrol-induced apoptosis by matrine in human hepatoma HepG2 cells. Oncol Rep 32: 2803-2809, 2014.

22. Niu H, Zhang Y, Wu B, Zhang Y, Jiang H and He P: Matrine induces the apoptosis of lung cancer cells through downregulation of inhibitor of apoptosis proteins and the Akt signaling pathway. Oncol Rep 32: 1087-1093, 2014.

23. Li H, Xie S, Liu $X$, Wu H, Lin $X, G u ~ J$, Wang $H$ and Duan Y: Matrine alters microRNA expression profiles in SGC-7901 human gastric cancer cells. Oncol Rep 32: 2118-2126, 2014

24. Zhang S, Cheng B, Li H, Xu W, Zhai B, Pan S, Wang L, Liu M and Sun X: Matrine inhibits proliferation and induces apoptosis of human colon cancer LoVo cells by inactivating Akt pathway. Mol Biol Rep 41: 2101-2108, 2014.

25. Zhang L, Wang T, Wen X, Wei Y, Peng X, Li H and Wei L: Effect of matrine on HeLa cell adhesion and migration. Eur J Pharmacol 563: 69-76, 2007.

26. Zhang S, Zhang Y, Zhuang Y, Wang J, Ye J, Zhang S, Wu J, Yu K and Han Y: Matrine induces apoptosis in human acute myeloid leukemia cells via the mitochondrial pathway and Akt inactivation. PLoS One 7: e46853, 2012.

27. Li Y, Zhang ZN, Zhao HM, Tong ZC, Yang J, Wang H and Liang XJ: Matrine inhibits the invasive properties of human osteosarcoma cells by downregulating the ERK-NF-kB pathway. Anticancer Drugs 25: 1035-1043, 2014.

28. Zhang S, Qi J, Sun L, Cheng B, Pan S, Zhou M and Sun X: Matrine induces programmed cell death and regulates expression of relevant genes based on PCR array analysis in C6 glioma cells. Mol Biol Rep 36: 791-799, 2009.

29. Xie M, He G, Wang R, Shi S, Chen J, Ye Y, Xie L, Yi X and Tang A: Matrine-induced apoptosis of human nasopharyngeal carcinoma cells via in vitro vascular endothelial growth factor-A/extracellular signal-regulated kinase1/2 pathway inactivation. Horm Metab Res 46: 556-560, 2014.

30. Keith RL: Chemoprevention of lung cancer. Proc Am Thorac Soc 6: 187-193, 2009

31. Saika K and Sobue T: Lung cancer: Progress in diagnosis and treatments. Topics I. Epidemiology and pathogenesis; 1. Epidemiology, prevention and screening. Nihon Naika Gakkai Zasshi 103: 1255-1260, 2014 (In Japanese).

32. Nykainen A, Räsänen J, Salo J and Sihvo E: Thoracoscopic surgery of lung cancer. Duodecim 130: 145-151, 2014 (In Finnish).

33. Pflaum J, Schlosser S and Müller M: p53 family and cellular stress responses in cancer. Front Oncol 4: 285, 2014

34. Farnebo M, Bykov VJ and Wiman KG: The p53 tumor suppressor: A master regulator of diverse cellular processes and therapeutic target in cancer. Biochem Biophys Res Commun 396: 85-89, 2010.

35. Cadwell $\mathrm{C}$ and Zambetti GP: The effects of wild-type p53 tumor suppressor activity and mutant p53 gain-of-function on cell growth. Gene 277: 15-30, 2001.

36. Marone M, Bonanno G, Rutella S, Leone G, Scambia G and Pierelli L: Survival and cell cycle control in early hematopoiesis: Role of bcl-2 and the cyclin dependent kinase inhibitors P27 and P21. Leuk Lymphoma 43: 51-57, 2002. 
37. Saegusa M, Hashimura M, Suzuki E, Yoshida T and Kuwata T: Transcriptional up-regulation of Sox9 by NF-kB in endometrial carcinoma cells, modulating cell proliferation through alteration in the p14 (ARF)/p53/p21 (WAF1) pathway. Am J Pathol 181: 684-692, 2012.

38. Dimitrova N, Zamudio JR, Jong RM, Soukup D, Resnick R, Sarma K, Ward AJ, Raj A, Lee JT, Sharp PA and Jacks T: LincRNA-p21 activates p21 in cis to promote Polycomb target gene expression and to enforce the G1/S checkpoint. Mol Cell 54: 777-790, 2014.

39. Chen W, Yoshida S, Ohara N, Matsuo H, Morizane M and Maruo T: Gonadotropin-releasing hormone antagonist cetrorelix down-regulates proliferating cell nuclear antigen and epidermal growth factor expression and up-regulates apoptosis in association with enhanced poly (adenosine 5'-diphosphate-ribose) polymerase expression in cultured human leiomyoma cells. J Clin Endocrinol Metab 90: 884-892, 2005.
40. Gao X, Dan S, Xie Y, Qin H, Tang D, Liu X, He QY and Liu L: $14-3-3 \zeta$ reduces DNA damage by interacting with and stabilizing proliferating cell nuclear antigen. J Cell Biochem 116: $158-169,2015$.

41. Oyama T, Mitsudomi T, Mizoue T, Ohgami A, Osaki T, Nakanishi R and Yasumoto K: Proliferating cell nuclear antigen may be superior to argyrophilic nucleolar organizer regions in predicting shortened survival of patients with non-small cell lung cancer. Surg Oncol 4: 83-89, 1995.

42. Sonenberg N: eIF4E, the mRNA cap-binding protein: From basic discovery to translational research. Biochem Cell Biol 86: 178-183, 2008.

43. Li Y, Fan S, Koo J, Yue P, Chen ZG, Owonikoko TK, Ramalingam SS, Khuri FR and Sun SY: Elevated expression of eukaryotic translation initiation factor $4 \mathrm{E}$ is associated with proliferation, invasion and acquired resistance to erlotinib in lung cancer. Cancer Biol Ther 13: 272-280, 2012. 